\title{
Double-balloon platform-assisted rectal endoscopic submucosal dissection
}

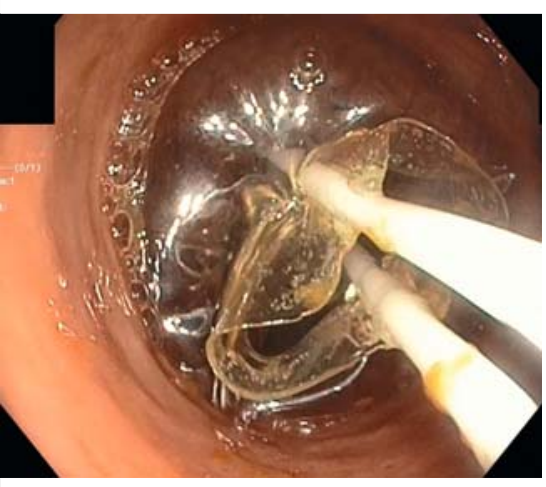

Fig. 1 Double-balloon platform deployed in the rectum.

A 69-year-old woman with complicated diverticular disease post-partial left colectomy was referred for evaluation of hematochezia. Index colonoscopy showed a large rectal polyp, and polypectomy was incomplete. Biopsy showed a traditional serrated adenoma. The case was referred to the advanced endoscopy service for further management.

The patient underwent a sigmoidoscopy that revealed a 40-mm, partially circumferential and lateral-spreading polypoid lesion, $0.5 \mathrm{~cm}$ from the dentate line. Endoscopic ultrasound (EUS) revealed a hypoechoic rectal mass with well-defined borders confined to the mucosa, which was amenable to endoscopic submucosal dissection (ESD).

Colonoscopy was then performed with the intention of undertaking ESD. A border around the lesion was initially marked using the soft coagulation setting. High pressure injection using a hybrid knife was used around the edges of the lesion; after adequate expansion of the submucosal space, the mucosa

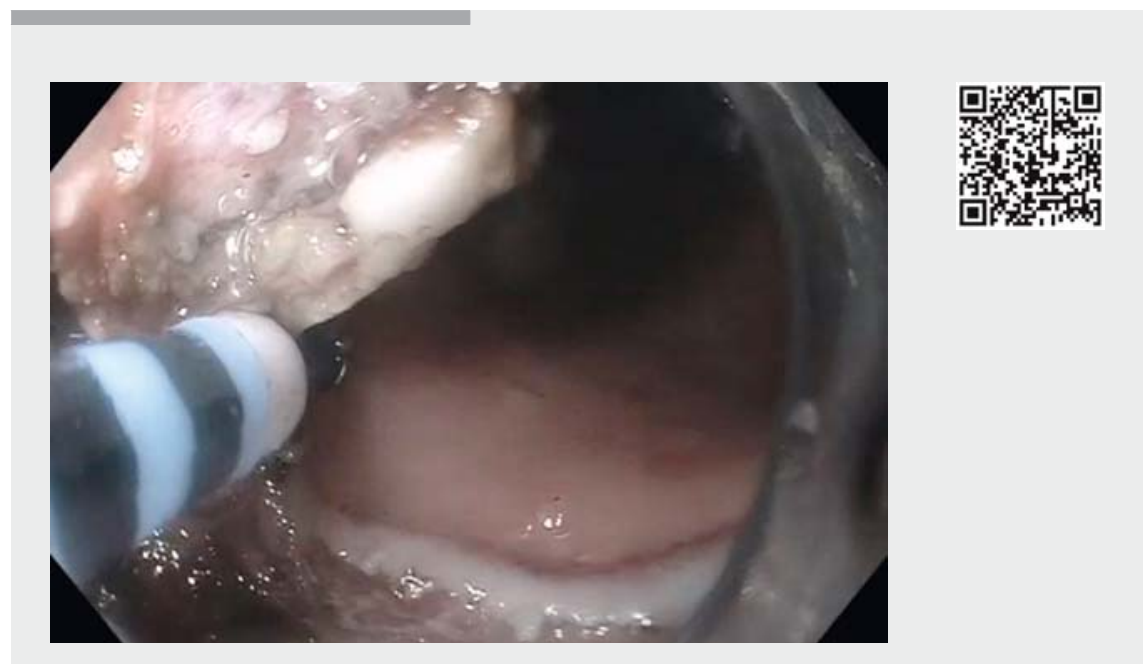

Video 1 Rectal endoscopic submucosal dissection of a serrated adenoma using a double-balloon platform.

was incised into the submucosa. After dissection had been started at the distal edge of the lesion, the double-balloon platform was deployed. The dissected edge was secured to the proximal balloon of the platform using hemoclips, and the device was used to retract the mucosa, facilitating further dissection. The submucosal space below the lesion was dissected using repeated submucosal injections followed by short bursts of dissection, and the lesion was ultimately removed en bloc ( $\triangleright$ Fig. 1 ; $>$ Video 1 ). One suture was placed to close the ESD defect.

The patient was discharged on day 2 and remained asymptomatic on follow-up. Pathology showed a $4.5 \times 2.5 \times 1-\mathrm{cm}$ serrated adenoma with margins that were free of adenomatous epithelium.
ESD can be safely and effectively used for en bloc excision of large colorectal tumors without submucosal invasion. However, the limitations of ESD include the currently available endoscopic accessories. Here, we demonstrate the successful application of the double-balloon platform to facilitate traction, provide stability, and allow for precise dissection of a large semi-circumferential rectal tumor.

Endoscopy_UCTN_Code_TTT_1AQ_2AD

Competing interests

Reem Z. Sharaiha is a consultant for Boston Scientific and Apollo Endosurgery. 
Corresponding author

Shawn L. Shah¹, Sam Sharma², Qais Dawod', Kaveh Hajifathalian ${ }^{1}$, Monica Saumoy ${ }^{1}$,

Toyooki Sonoda ${ }^{2}$, Reem Z. Sharaiha ${ }^{1}$

1 Division of Gastroenterology \& Hepatology, New York Presbyterian-Weill Cornell Medical Center, New York, New York, USA

2 Department of Surgery, New York Presbyterian-Weill Cornell Medical Center, New York, New York, USA
Reem Z. Sharaiha, MD

1305 York Ave, 4th Floor, New York, NY, 10065, USA

rsharaiha@gmail.com

\section{Bibliography}

DOI https://doi.org/10.1055/a-0606-4862

Published online: 28.6.2018

Endoscopy 2018; 50: E252-E253

(c) Georg Thieme Verlag KG

Stuttgart · New York

ISSN 0013-726X

\section{ENDOSCOPY E-VIDEOS}

https://eref.thieme.de/e-videos

回回 Endoscopy E-Videos is a free access online section, reporting 靣: on interesting cases and new techniques in gastroenterological endoscopy. All papers include a high quality video and all contributions are freely accessible online.

This section has its own submission website at

https://mc.manuscriptcentral.com/e-videos 